\title{
Assessing Cancer Risk in China from $\gamma$-Hexachlorocyclohexane Emitted from Chinese and Indian Sources
}

Yue $\mathrm{Xu},{ }^{\dagger \neq}$ Chongguo Tian, ${ }^{*}{ }^{\dagger}$ Jianmin $\mathrm{Ma},{ }^{\S}$ Xiaoping Wang, ${ }^{\ddagger}$ Jun Li, ${ }^{\ddagger}$ Jianhui Tang, ${ }^{\dagger}$ Yingjun Chen, ${ }^{\dagger}$ Wei Qin, ${ }^{\dagger}$ and Gan Zhang

${ }^{\dagger}$ Key Laboratory of Coastal Zone Environmental Processes and Ecological Remediation, Yantai Institute of Coastal Zone Research (YIC), Chinese Academy of Sciences (CAS); Shandong Provincial Key Laboratory of Coastal Zone Environmental Processes, YICCAS, Yantai Shandong 264003, P. R. China

${ }^{\ddagger}$ State Key Laboratory of Organic Geochemistry, Guangzhou Institute of Geochemistry, Chinese Academy of Sciences, Guangzhou, 510640, China

${ }^{\S}$ Air Quality Research Division, Science and Technology Branch, Environment Canada, 4905 Dufferin Street, Toronto, Ontario, M3H 5T4, Canada

\section{Supporting Information}

ABSTRACT: Three models, including an atmospheric transport model, a multimedia exposure model, and a risk assessment model, were used to assess cancer risk in China caused by $\gamma-\mathrm{HCH}$ (gamma-hexachlorocyclohexane) emitted from Chinese and Indian sources. Extensive model investigations revealed the contribution of different sources to the cancer risk in China. Cancer risk in Eastern China was primarily attributable to $\gamma$-HCH contamination from Chinese sources, whereas cancer risk in Western China was caused mostly by Indian emissions. The contribution of fresh use of lindane in India to the cancer risk in China was almost 1 order of magnitude higher than that of the reemission of $\gamma-\mathrm{HCH}$ from Indian soils. Of total population, $58 \%$ (about 0.79 billion) residents in China were found to live in the environment with high levels of cancer risk exceeding the acceptable cancer risk of $10^{-6}$, recommended by the United States Environmental Protection Agency (U.S. EPA). The cancer risk in China was mostly induced by the local contamination of $\gamma-\mathrm{HCH}$ emitted from Chinese sources, whereas fresh use of lindane in India will become a significant source of the cancer risk in China if Indian emissions maintain their current levels.

\section{INTRODUCTION}

Environmental exposure to toxic contaminants has received considerable attention in recent decades because of the significant risk factors in the etiology of several chronic diseases, for example, cancer, ${ }^{1}$ cardiovascular disease, ${ }^{2}$ chronic respiratory disease, ${ }^{3}$ and diabetes. ${ }^{4}$ These chronic diseases account for $60 \%$ of the deaths worldwide, and $80 \%$ of these deaths occur in low- or middle-income countries. ${ }^{5}$ In China, the largest developing country in the world, chronic diseases were responsible for $70 \%$ of total mortality and $60 \%$ of total disease burden in 2002. ${ }^{6}$ The Chinese mortality from cancer and cardiovascular disease in 2009 was reported to have a 2 -fold increase compared with that in $1990 .^{7}$ This inspired a number of studies on the connections between human health risk and exposure levels to toxic contaminants in China. ${ }^{1,8}$ Recently, the health benefits from air pollution control have generated considerable research interest. ${ }^{1,9}$ However, previous reports only considered the effect of trans-provincial transport of air contaminants on human health in China. ${ }^{9}$ Little attention has been paid to the influence of the trans-boundary transport of contaminants on human health.
Persistent organic pollutants (POPs) are hardly broken down in the environment and can undergo long-range atmospheric transport (LRAT). ${ }^{10}$ This leads to the presence of POPs not only in their source regions but also in pristine areas far from the sources. Even low environmental levels of these pollutants can pose a considerable threat to human health and the ecosystem because they tend to be accumulated in lipid-rich tissues of biota and biomagnified through terrestrial and aquatic food chains. ${ }^{11,12}$ While human health risk caused by POPs was generally studied on food, human blood, or other tissues on a local range, separately, an integrated regional assessment is still limited.

Indian monsoon provides a route of favorable atmospheric transport from India to China in spring and summer. ${ }^{13}$ Higher atmospheric concentration levels of many POPs in India ${ }^{14-17}$ than in China ${ }^{18}$ would yield significant deposition of these contaminants to Chinese environment through LRAT. ${ }^{19} \gamma$ -

Received: January 9, 2013

Revised: $\quad$ May 22, 2013

Accepted: May 28, 2013

Published: May 28, 2013 
Hexachlorocyclohexane $(\mathrm{HCH})$, listed as a new POP by the Stockholm Convention in 2009, is one of the toxic chemicals extensively used in India ${ }^{14-17}$ and China. ${ }^{18}$ Two formulations of $\mathrm{HCH}$, technical $\mathrm{HCH}$ and lindane, have been used widely to control agricultural and public health pests, and hence formed most $\gamma-\mathrm{HCH}$ in the environment. ${ }^{20}$ Generally, technical $\mathrm{HCH}$ contains $8-15 \%$ of $\gamma-\mathrm{HCH}$ and lindane is almost pure $\gamma-\mathrm{HCH}$. Technical $\mathrm{HCH}$ was banned globally before 2000, and China and India were the largest producers and users of this pesticide in the world. ${ }^{20}$ The restricted use of lindane is still permitted in India due to its low cost for disease control, ${ }^{17,21}$ although the use in China has been stopped since 2003. ${ }^{22}$ This enables us to assess the health risk of $\gamma-\mathrm{HCH}$ in China emitted from China and India, the two major sources of this chemical in the world. ${ }^{20}$ In general, there were limited regional atmospheric monitoring programs to assess temporal and spatial patterns of $\gamma-\mathrm{HCH}$ in China and India. Relatively abundant data on regional atmospheric concentrations of $\gamma-\mathrm{HCH}$ in China and India were reported during 2005-2007 from several field campaigns. ${ }^{14,16-18}$ To better evaluate model results using this measured data, the model was run from 2005 to 2007 in this investigation. The present study aims at assessing cancer risk in China induced by $\gamma-\mathrm{HCH}$ emitted from different sources during 2005-2007 using three models which will be described below. The major objectives are (1) to establish a spatial pattern of the cancer risk level across China, (2) to distinguish the contribution of $\gamma-\mathrm{HCH}$ sources in China and India to the cancer risk in China, and (3) to predict the temporal trend of the cancer risk in China emitted from Chinese and Indian sources.

\section{MATERIALS AND METHODS}

In the present study, three models, including an atmospheric transport and fate model, a multimedia exposure model, and a risk assessment model, have been used to assess $\gamma$ - $\mathrm{HCH}$ concentrations in the air, soil, water, and food, as well as average daily doses (ADDs) and the cancer risk. A horizontal resolution of $1 / 4^{\circ}$ latitude by $1 / 4^{\circ}$ longitude was adopted in the three models. The atmospheric transport model domain spans 0 to $60^{\circ} \mathrm{N}$ and 50 to $150^{\circ} \mathrm{E}$, covering the entire China and India as shown in Supporting Information (SI) Figure S1. The multimedia exposure model and risk assessment model cover only China.

2.1. Atmospheric Transport Model. $\gamma-\mathrm{HCH}$ concentration levels in the air and soil as well as its atmospheric transport and deposition during 2005-2007 were predicted by a modified version of Canadian Model for Environmental Transport of Organochlorine Pesticides (CanMETOP). The model was originally developed as a regional scale atmospheric transport model covering the North American continent ${ }^{23}$ and has been extended to global scale to investigate intercontinental long-range transport of lindane (considered as a product containing pure $\gamma-\mathrm{HCH}){ }^{10}$ The model framework used in this study is the same as that adopted in the global version of CanMETOP ${ }^{10}$ but the model domain has been reduced to China/India region (see SI Figure S1) with a grid resolution of $1 / 4^{\circ}$ latitude by $1 / 4^{\circ}$ longitude. Briefly, the CanMETOP is a three-dimensional atmospheric dispersion model coupled with a dynamic, three soil layers, fugacity-based mass balance soil-air exchange model, and a two-film model to estimate water-air gas exchange. In the vertical, a terrain-following coordinate is used and 14 vertical model levels from the surface to $11 \mathrm{~km}$ are adopted. The environmental processes included in the model are transport and turbulent diffusion in the atmosphere, dry and wet deposition, and exchange at the interfacial boundaries of air-water and soil-air, and removal processes in the air and water via degradation as well as from the soil via diffusion, leaching, and degradation.

The meteorological data (including wind, pressure, temperature, precipitation, etc.) were the 6-hourly objectively analyzed data from the National Centers for Environmental Prediction (NCEP) reanalysis. ${ }^{24}$ Details can be found at http://www.esrl. noaa.gov/psd/data/gridded/data.ncep.reanalysis.html. The data were then interpolated to the model grids and time intervals $\left(1 / 4^{\circ} \times 1 / 4^{\circ}\right.$ latitude/longitude and 20 -min time step). Soil residue inventory of $\gamma-\mathrm{HCH}$ with $1 / 4^{\circ} \times 1 / 4^{\circ}$ latitude/ longitude in 2005 (see SI Figure S2) was used as initial conditions for the model integration. Since technical $\mathrm{HCH}$ and lindane were mainly used as pesticides in Asia, the inventory was created by splitting a global soil inventory with $1^{\circ} \times 1^{\circ}$ latitude/longitude using the area ratios of cropland from the gridded land use data. ${ }^{25}$ The global inventory was obtained from the historical use of technical $\mathrm{HCH}$ and lindane and updated by measured soil data of $\gamma-\mathrm{HCH}$ in China. ${ }^{10}$ The global inventory was used to examine intercontinental LRAT of $\gamma$-HCH. ${ }^{10}$ Since China and India have been identified as major sources of $\gamma$-HCH globally, and their external sources only exert a weak influence on the $\gamma-\mathrm{HCH}$ budget in the environment of the model domain, the external sources are not considered here. ${ }^{20}$ Initial $\gamma-\mathrm{HCH}$ concentrations in lake and sea were not taken into account due to insignificant $\gamma-\mathrm{HCH}$ reemission from these water bodies across China. ${ }^{26,27}$ The numerical simulations were performed for the period of December 1, 2004 to December 31, 2007 with the first month as the model spin up period. The model spin up period is taken in each simulation to eliminate any effects from the initial conditions. ${ }^{10}$ SI Table S1 lists the physicochemical properties of $\gamma-\mathrm{HCH}$ used in the modeling.

2.2. Multimedia Exposure Model. The exposure model took into account 14 possible routes that lead to the accumulation of $\gamma-\mathrm{HCH}$ in the human body. These were ingestion of cereal, vegetable, edible oil, fruit, fish, meat, milk, egg, and drinking water; inhalation through air and airborne particles; and dermal contact with airborne particles, soil, and bath water. Though there are certain amounts of food circulation for resident consumption among regions in China or from foreign import, the exact data are unavailable. Hence, we assumed that the cancer risk at each model grid point resulted from local contamination of $\gamma-\mathrm{HCH}$ in the atmosphere, water, soil, and food. $\gamma-\mathrm{HCH}$ concentrations in the water, plant food, and fish were calculated using a level III fugacity method. Beef, pork, and chicken, which are the prevailing animal foods for Chinese, were considered in the model as meat. Concentrations of $\gamma-\mathrm{HCH}$ in meat, milk, and egg were estimated by assuming the accumulation of $\gamma-\mathrm{HCH}$ in related animals (livestock) in the model. The ADD in receptors through the 14 exposure routes were also estimated in the model. Details are described in section SI2 of SI.

2.3. Risk Assessment Model. The cancer risk is defined to be equal to the product of the $\mathrm{ADD}$ and the cancer slope factors, which represent the number of incidences of cancer. ${ }^{28}$ For instance, a cancer risk of $10^{-6}$, the acceptable cancer risk recommended by the U.S. EPA, corresponds to one incidence of cancer per million people due to the agent being assessed. For every exposure route, the same cancer slope factor of 1.3 (per mg kg ${ }^{-1} \mathrm{day}^{-1}$ ) for $\gamma-\mathrm{HCH}$, recommended by the U.S. 
EPA (www.epa.gov/iris/), was adopted. The total cancer risk arising from the 14 exposure routes to environmental contamination of $\gamma-\mathrm{HCH}$ was used to elucidate and assess the health risk of Chinese population.

2.4. Model Evaluation. Increasing $\gamma-\mathrm{HCH}$ air concentrations in China occurred in the autumn, ${ }^{18}$ whereas in India the $\gamma$ - $\mathrm{HCH}$ level in air increased during the autumn-winter period. ${ }^{15,17}$ Here we proposed that the seasonal increase of the air concentrations could be a result of the enhanced reemission from soil due to cropland cultivation during autumn harvest and planting of winter-wheat, or the direct emission owing to lindane use. ${ }^{16}$ To address the increase of $\gamma-\mathrm{HCH}$ air concentrations in both countries in cold seasons, several numerical experiments were performed. The modeled atmospheric levels of $\gamma-\mathrm{HCH}$ were compared with measured data to test our hypothesis. The spearman rank correlation method was applied for the assessment since this nonparametric statistical technique is applicable to data with linear or nonlinear trends, and is insensitive to outliers.

The production of lindane was stopped by Chinese manufactures in 2003 due to its low profit. In that year the stock was estimated to be about $100 \mathrm{t}$ in China. ${ }^{22}$ This suggests that the increase of $\gamma-\mathrm{HCH}$ air concentration in China in autumn could be a result of the enhanced reemission from soil due to cropland cultivation during autumn harvest and planting of winter-wheat or the direct emission owing to the illegal use of the pesticide. ${ }^{29}$ Because of low stock of lindane in China, ${ }^{22}$ we postulated that $\gamma-\mathrm{HCH}$ reemission due to cropland cultivation contributed primarily to its changes in the atmosphere. This has been verified by two numerical experiments without and with cropland cultivation (see section SI3.1) using the $\gamma$ - $\mathrm{HCH}$ soil residue in 2005 .

SI Figure S4 displays the correlations between modeled and measured air concentrations of $\gamma-\mathrm{HCH}$. Significant correlations between modeled and measured concentrations over the model domain suggest that the soil inventory reflects fairly well the spatial distribution of $\gamma-\mathrm{HCH}$ (see SI Figure S4 a and d). Modeled $\gamma-\mathrm{HCH}$ concentrations in the atmosphere from the numerical experiment considering cropland cultivation matched better with the measured data within China compared with that not accounting for cropland cultivation (see SI Figure S4 b and e and Figure S5). Further assessment was carried out by comparing modeled and measured $\gamma-\mathrm{HCH}$ air concentrations at Ocean University of China $\left(36^{\circ} 3^{\prime} \mathrm{N}, 120^{\circ} 20^{\prime} \mathrm{E}\right)$ in Qingdao, China. The model simulation with cropland cultivation in autumn matched well with measured $\gamma-\mathrm{HCH}$ air concentrations after October, which was not caught by the model scenario without cropland cultivation, as shown in SI Figure S6.

The predicated atmospheric concentrations by the numerical experiments without and with cultivation were inconsistent with measured data in India (see SI Figure S4 c and f). The lack of agreement can be attributed to a sharp increase in air concentrations during autumn-winter in India, ${ }^{14-17}$ indicating current widespread and intensive use of lindane in the country. Cropland cultivation intensity and population density were often used as surrogate parameters to build the spatial patterns of the use or emission of POPs. However, we found no significant correlation between spatial patterns of $\gamma-\mathrm{HCH}$ air concentration in India sites (SI Figure S3) and Indian cropland cultivation intensity, as well as human population density with $1 / 4^{\circ} \times 1 / 4^{\circ}$ latitude/longitude. Thus, we split the time series of the mean $\gamma-\mathrm{HCH}$ air concentration (SI Figure S7) collected from those sampling sites in India (SI Figure S3) into two periods according to the concentration levels, and calculated the statistical values for the two periods (SI Table S5). Based on the simulation with the cropland cultivation as mentioned previously, three model scenarios which add measured mean, maximum, and minimum $\gamma$-HCH concentrations (SI Table S5) to the model atmosphere over India were performed in order to simulate primary air emission of lindane in India. Details are presented in SI.

We compared only the results of the three model scenarios with measured $\gamma-\mathrm{HCH}$ concentrations within India. The correlation and statistical results of measured and modeled air concentrations of $\gamma-\mathrm{HCH}$ are showed in SI Figure S8 and Table S6, respectively. The improvements to the modeled air concentrations can be seen for all three model scenarios as compared with that accounting for cropland cultivation. The results from the scenarios adding measured maximum and minimum concentrations in the respective modeling scenarios yielded a better correlation with the measured atmospheric levels (SI Figure S8). The modeled air concentrations from the scenarios adding measured maximum and minimum concentrations were markedly higher and lower than the measured levels (SI Table S6). We then applied the binary linear regression to gain model concentration levels comparable to the measurements in India. It was found that the ensemble results of model scenarios, that are measured maximum $\times 0.2+$ minimum concentrations $\times 0.8$, were better than other model scenario results (see SI Figure S8 and Table S6).

To further establish the level of confidence for introducing the hypothesis of increasing $\gamma-\mathrm{HCH}$ air concentration in China and India during the cold season, the air concentrations simulated by the model scenarios adding measured maximum and minimum concentrations and their ensemble were compared with the measurements over the model region. Results are plotted in SI Figure S9. It was found that the modeled concentrations from the three modeling scenarios matched well with the measured ones. The Spearman correlation coefficients are $0.54(p<0.001), 0.55(p<$ $0.001)$, and $0.63(p<0.001)$ for the model scenario adding measured maximum and minimum concentrations and their ensemble, respectively. Accordingly, the median ratios of the air concentrations from the three modeling scenarios to the monitored data are 1.8, 0.5, and 1.0 (SI Figure S10). These higher correlations and median ratios of the modeled to measured data indicated that the three model scenarios significantly enhanced the accuracy of prediction for $\gamma-\mathrm{HCH}$ air concentration, as compared with the results derived from the model scenario considering cropland cultivation (see SI Figure S4, S9, and S10). Given that the ensemble results reflected better the geographical pattern of sampled concentration levels, we can assume that these modeling results provide a more realistic picture of $\gamma-\mathrm{HCH}$ in the Indian environment, whereas the results from the model scenarios adding measured maximum and minimum concentrations possibly reflect upper and lower limits of the $\gamma-\mathrm{HCH}$ atmospheric level in India, respectively. As a result, we considered that the model scenarios adding measured maximum and minimum concentrations and their ensemble featured the impact of maximal, minimal, and moderate primary emission of lindane in India, respectively, on the atmospheric levels of $\gamma-\mathrm{HCH}$.

2.5. Numerical Experiment Setup. Since the governing equations in the modeling system are linear, the solutions can be linearly combined to determine the contributions from 
individual sources through different model scenarios. Five model scenarios were designated to assess the cancer risk derived from different sources of $\gamma$ - $\mathrm{HCH}$. These scenarios consist of model scenario 1 (M1) which took into consideration soil residues emission of $\gamma-\mathrm{HCH}$ due to cropland soil cultivation activities in autumn; model scenarios 2-4 with moderate (M2), maximal (M3), and minimal (M4) air emission of lindane in India combining with $\mathrm{M1}$; and model scenario 5 (M5) which only considered Chinese sources in the $\gamma$-HCH soil residue inventory based on M1. SI Table S7 lists these model scenarios. The cancer risk levels simulated by M2 can provide an insight into an overall picture of the cancer risk in China. The results from M1 and M5 addressed the contribution of the historical soil residues of $\gamma-\mathrm{HCH}$ in the model domain and China, respectively. The results from M3 and M4 were designed to assess the contribution of potential upper and lower limit of the air emission of lindane in India to the cancer risk in China, respectively.

2.6. Uncertainty Analysis. The uncertainty of the cancer risk was estimated by using Monte Carlo simulation. To understand the difference between the uncertainties associated with input model parameters of the CanMETOP model, multimedia exposure model, and risk assessment model, two additional model scenarios were introduced. The first scenario considered the input parameters of the CanMETOP as variables and the other two models input parameters as constants. The other scenario considered all the input parameters of the three models as variables. Each model scenario was run 1000 times repeatedly. For simplicity, total cancer risk (TCR) calculated by both model scenarios was used to assess the uncertainties. Results show that the TCR uncertainty was primarily attributed to the variability of intake rate and associated with exposure levels. Details are presented in the section SI8 of SI.

\section{RESULTS AND DISCUSSION}

3.1. Modeled Cancer Risk and Statistical Cancer Mortality Rate. Modeled total cancer risks derived from the model scenario M2 were compared with statistical cancer mortality in China. The statistical cancer mortality rates were collected from literature. The estimated cancer risk agreed well (Spearman correlation coefficient $=0.49, p<0.001$ ) with the 58 statistical cancer mortality rates covering most provinces, cities, and municipalities in China, as shown in SI Figure S11. The median ratio of the estimated cancer risk to the statistical cancer mortality rates in China was $8 \%$, ranging from $0.02 \%$ to $48 \%$ as shown in SI Figure S12.

It has been known that many cancers result from the interaction of genetic and acquired susceptibility and all environmental carcinogens. Although there is a significant correlation and high ratio of a carcinogenic contaminant to mortality or incidence of cancer, one cannot deduce that contaminants would lead to mortality or incidence of cancer. It is worth noting that the geographical patterns of toxic contaminants, e.g., technical $\mathrm{HCH}$, polycyclic aromatic hydrocarbons (PAHs), polychlorinated biphenyls (PCBs), mercury, and others, are similar in China. These toxic chemicals could lead to multiple exposure risk. For instance, the increase in cytokinesis-block micronuclei resulting from the binary mixtures of benzo[a]pyrene $(\mathrm{BaP})$ plus $\gamma-\mathrm{HCH}$ is 2 - to 5fold higher than that by $\mathrm{BaP}$ only. ${ }^{30}$ This may suggest that $\gamma$ $\mathrm{HCH}$ could play an important role in human health risk in those regions where both $\mathrm{BaP}$ and $\gamma-\mathrm{HCH}$ are rich by interacting with each other to increase the risk potential. Exposure risk to $\mathrm{PAHs}$, including $\mathrm{BaP}$, in China has attracted increasing concern recently ${ }^{1,8}$ due to their high emissions in the country. The spatial distribution of inhalation exposure to $\mathrm{PAHs}^{8}$ exhibits a similar spatial pattern as that of cancer risk induced by $\gamma-\mathrm{HCH}$ (see Figure 1). This again emphasizes the importance of multiple exposure risks from multiple contaminants on mortality or incidence of cancer. ${ }^{30}$
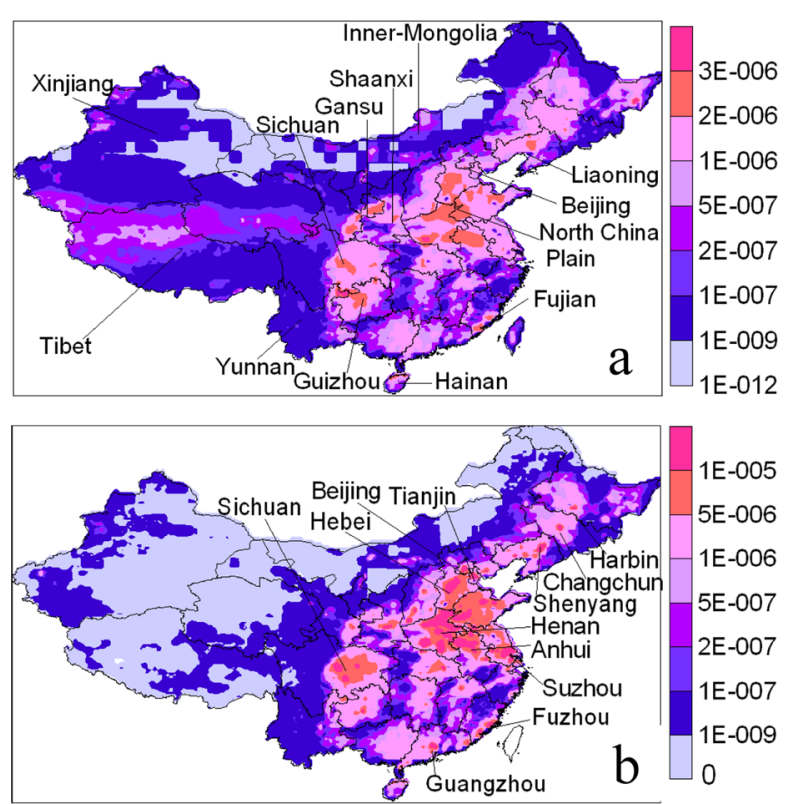

Figure 1. Spatial pattern of averaged cancer risk (dimensionless, a) and population-weighted cancer risk (dimensionless, b) in China induced by $\gamma-\mathrm{HCH}$ in $2005-2007$.

3.2. Geographical Pattern of Cancer Risk. The geographical pattern of averaged cancer risk during 2005-2007 in China was computed from M2 model scenario and plotted in Figure 1a. In Figures S13-16 we also plotted corresponding spatial patterns of modeled $\gamma-\mathrm{HCH}$ concentrations in the air, soil, and water, as well as atmospheric depositions (wet + dry) averaged over 2005-2007. High cancer risk values suggest high probability of cancer incidence and mortality. In general, the modeled cancer incidence and mortality in Eastern China was higher than that in Western China. The ingestion of cereal was a major exposure route to the cancer risk in Eastern China, which was similar to a previous assessment using measured data in Tianjin, ${ }^{31}$ while ingestion of drinking water and inhalation of air contributed a considerable proportion of the cancer risk in Western China (SI Figure S17). Considerable high cancer incidence and mortality $\left(>2 \times 10^{-6}\right)$ were simulated primarily in the Northern China plain, East Sichuan, Northwest Guizhou, and Midnorth Liaoning, where a large amount of lindane was used to prevent wheat midge infestation before 2003. ${ }^{22}$ Although the total area of those regions accounts for only about $11 \%$ of the land area of China, estimated $\gamma-\mathrm{HCH}$ soil residues in these regions account for about $30 \%$ of the total residues in the country. In addition, $44 \%$ of the national human population resides in these regions. The modeled risk levels induced by $\gamma-\mathrm{HCH}$ were also comparable with previous monitoring studies. The cancer risks of $\gamma-\mathrm{HCH}$ were $3.9 \times$ $10^{-6}$ in Beijing and $2.1 \times 10^{-6}$ in Shenyang, the capital of Liaoning Province, calculated by the ADD using measured food 
samples in these two metropolitan cities in 2005-2007..$^{32}$ Using measured food data in 2008, Liu et al. estimated population exposure to $\gamma-\mathrm{HCH}$ in Taiyuan, the capital of Shanxi Province, and obtained an ADD of $4.4 \times 10^{-6} \mathrm{mg} /$ $(\mathrm{kg} \cdot \mathrm{d})$, which is equivalent to a cancer risk of $5.7 \times 10^{-6} .^{33} \mathrm{In}$ addition, the model simulation indicated that the LRAT and subsequent deposition also led to the occurrence of the cancer incidence and mortality ranging from $1 \times 10^{-9}$ to $1 \times 10^{-6}$ in the greatest area of Western China, extending from Yunnan and Tibet to Xinjiang and Inner Mongolia, where no historical use of the pesticide was reported (see SI Figure S2). Substantially low cancer incidence and mortality $\left(<1 \times 10^{-9}\right)$ were predicted mainly in the desert area of Northwest China. The dry meteorological condition and lower organic carbon content in the soil are mainly responsible for the lower cancer risk level in this area.

To understand the overall risk in densely populated areas, population-weighted cancer risk was calculated as the products of the predicted cancer risk and population density divided by national average population density. The calculated populationweighted cancer risk is presented in Figure $1 \mathrm{~b}$. The high population-weighted cancer risk values $\left(>10^{-5}\right)$ were mostly concentrated in Henan, the province with the highest population in China and those megalopolis in Northeastern China (e.g., Shenyang, Changchun, and Harbin), Eastern China (e.g., Beijing and Tianjin), Southeastern China (e.g., Guangzhou and Fuzhou), and cities in East Sichuan Basin because of spatial overlap of the high cancer risk level and high population density. Such spatial overlap of high environmental exposure to toxic contaminants and high population density ${ }^{8}$ seems to be an important cause of chronic diseases that result in primary mortality and disease burden in China. ${ }^{6}$

3.3. Contribution of Different Sources to Cancer Risk. Figure 2a presents the percentage of the cancer risk calculated from the cancer risk ratio predicted by the model scenario M5 to that from M2, namely, M5/M2 × 100. The figure highlights the contribution of Chinese $\gamma-\mathrm{HCH}$ sources to the cancer risk in China. As shown, the Chinese sources made a major contribution to the cancer risk in Eastern China and Northwestern China (>99\%). The decreasing spatial trend from the east to the west is because the $\gamma-\mathrm{HCH}$-laden air mass from the source regions in Eastern China seldom migrates to Western China (e.g., the Tibetan Plateau) under the prevailing westerly wind over midlatitudes and increasing terrain height toward the Tibetan plateau.

To quantitatively determine the contribution of the $\gamma-\mathrm{HCH}$ emitted from different Indian sources to the cancer risk in China, in Figure $2 b$ and $c$ we illustrate values of (M2 - M1)/ M2 $\times 100$ and $(M 1-M 5) / M 2 \times 100$, characterizing the cancer risk percentages inferred by LRAT under moderate air emission of lindane and reemission of $\gamma$ - $\mathrm{HCH}$ from India, respectively. Generally, Indian sources contributed to a majority of the cancer risk in Western and Southwestern China. We have demonstrated previously that Indian sources could result in remarkably higher deposition of $\gamma-\mathrm{HCH}$ to Southern China than any other sources in China. ${ }^{34}$ The result from the present study further confirms that India is an important source of POPs contamination to the Tibetan plateau and the influence of Indian emissions could extend to midwest Sichuan. ${ }^{34,35}$ In the case of the spatial pattern of the cancer risk, the present modeling results illustrate stronger contribution from the current use of lindane in India to the cancer risk in Western China. The contribution is almost 1 order of magnitude higher

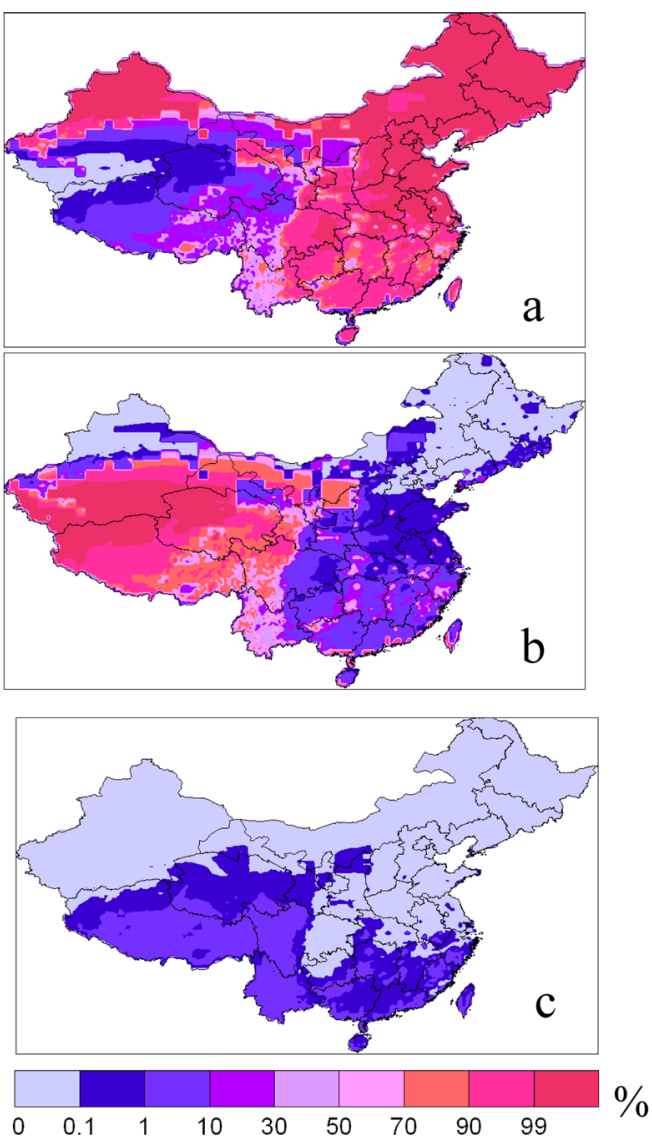

Figure 2. Percentage of cancer risk caused by Chinese source of $\gamma$ $\mathrm{HCH}$ (a), moderate air emission of lindane in India (b), and reemission of $\gamma-\mathrm{HCH}$ from soils in India (c).

than that from the reemission of $\gamma-\mathrm{HCH}$ from previously contaminated soils in India (SI Figure $2 \mathrm{c}$ ). The contribution patterns (SI Figure S18) of the potential maximal and minimal air emission of lindane in India, as expected, are similar to that simulated by the moderate air emission of lindane in India, as shown in Figure2b.

3.4. Statistical Cancer Risk. Having discussed the spatial pattern of the cancer risk in China and the contribution from the different sources of $\gamma-\mathrm{HCH}$, it is also interesting to know human population and geographical area exposed to different levels of the cancer risk, and to examine the contribution of different $\gamma-\mathrm{HCH}$ sources to the population and area exposed to these cancer risk levels. To do so, we analyzed the population and area proportions exposed to different ranges of the estimated cancer risk from three model scenarios of M2, M3, and M5. Results are illustrated in Figure 3. From the M2 simulation, $58 \%$ (about 0.79 billion) of the total Chinese population were exposed to the $\mathrm{CR}>10^{-6}$, exceeding the acceptable cancer risk recommended by the U.S. EPA. Those people reside in only $16 \%$ of the total area in China, including the Northern China plain and Sichuan as previously mentioned. The statistical population and area distributions exposed to the cancer risk incurred by the Chinese emission source (M5: only considered Chinese sources) were identical to that simulated by the other two model scenarios (M2 and M3: considering moderate and maximal air emission of lindane in India), suggesting that the human exposure to different cancer risk levels were largely dominated by Chinese $\gamma-\mathrm{HCH}$ emission 


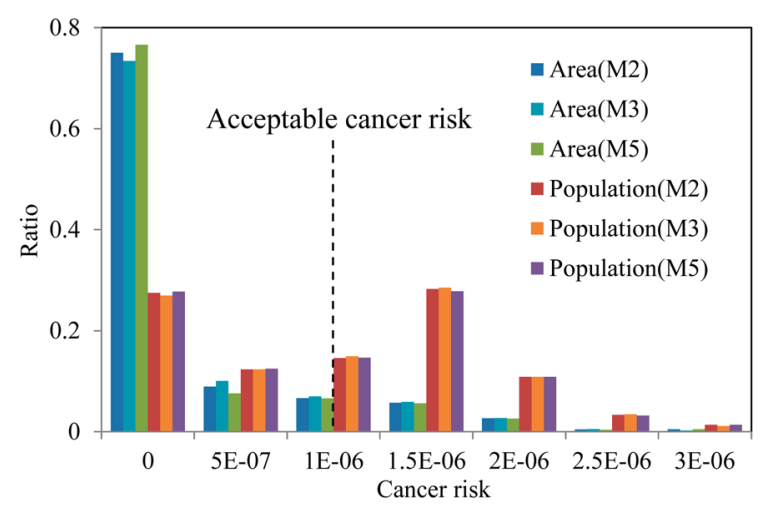

Figure 3. Histogram of human population and areas in China exposed to different cancer risk levels using emission sources selected in model scenarios M2, M3, and M5. $x$-axis represents the cancer risk ranges and $y$-axis represents the ratio of populations and areas exposed to each range to total populations and areas in China.

source. The Indian sources only made a minor contribution to the human risk in China.

The accumulated products of the cancer risk and the population within each grid cell in China were divided by the total national population to evaluate the total cancer risk associated with population (TCRP) in China. By comparison of the TCRP derived from different model scenarios, the contribution from the different sources of $\gamma-\mathrm{HCH}$ to the TCRP can be quantified. Averaged TCRP during 2005-2007 was attributed mostly to Chinese sources (M5) which accounted for $99.57 \%$ of the TCRP estimated by M3. Compared with the TCRP derived from M5, the TCRPs contributed by the air emission of lindane from India were $0.43 \%, 1.72 \%$, and $0.11 \%$ derived from M2, M3, and M4, respectively. The contribution from $\gamma-\mathrm{HCH}$ reemission from Indian soils was only $0.06 \%$. The rest of the sources excluding India and China contributed to $0.003 \%$ of the TCRP. We further calculated the accumulated product of the cancer risk and the area within each grid cell in China divided by the total national area, in order to evaluate total cancer risk associated with area (TCRA) and the source contribution. The Chinese sources (M5) again ranked as the largest contributor which accounted for $89 \%$ of the TCRA derived from the M2 simulation, followed by the Indian sources (11\%). The rest of the sources in the model domain only contributed $0.02 \%$ of the TCRA from the M2 simulation.

3.5. Temporal Trend of Cancer Risk. Figure 4a displays modeled annual TCRP and TCRA during 2005-2007 derived from M1, M2, and M5 simulations. Generally, the TCRPs and TCRAs computed from the three model scenarios exhibited declining trends, largely caused by the decreasing total environmental burden of $\gamma-\mathrm{HCH}$ in China due to the overall degradation in the environment since the cease of application of lindane in the country. The stronger decreasing trend of the TCRPs comparing to the TCRAs was primarily attributed to the contribution of Indian emission sources of $\gamma-\mathrm{HCH}$ to the cancer risk in Western China and stronger decline of $\gamma-\mathrm{HCH}$ environmental levels in Eastern China with higher population density. The TCRPs and TCRAs derived from the M1, M2, and M5 simulations showed the same decreasing trend, suggesting that their temporal changes could be mainly attributed to the local $\gamma-\mathrm{HCH}$ residues in China.

Figure $4 \mathrm{~b}$ illustrates the fractions of the TCRP and TCRA from 2005 to 2007, defined as (M2 - M1)/M2 × 100 and (M1
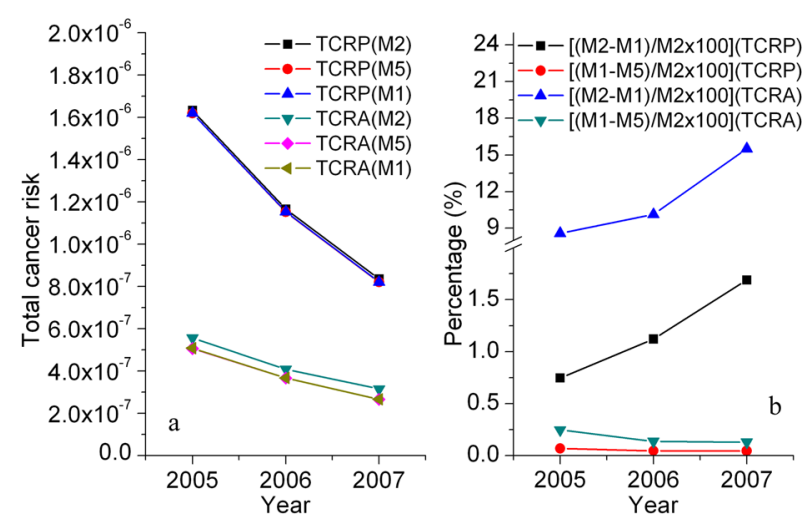

Figure 4. Annual total cancer risk associated with population (TCRP) and total cancer risk associated with area (TCRA) (a), and contribution percentages of moderate use of lindane within India (M2 - M1) and reemission of $\gamma-\mathrm{HCH}$ from Indian soil (M1 - M5) to TCRP and TCRA (b) during 2005-2007.

$-\mathrm{M} 5) / \mathrm{M} 2 \times 100$. These ratios describe the contributions of the moderate lindane air emission and the reemission within India to the cancer risk in China. As shown, as the contributions of the Indian reemission to the TCRP and TCRA declined monotonically, the contribution from the air emission of lindane within India to the TCRP and TCRA increased from 2005 through 2007. The lindane air emission to the TCRA played a more important role than other factors because the Indian sources contributed mostly to the cancer risk of Western China where there are considerably lower human populations. The increase of the TCRP and TCRA induced by Indian air emission and estimated by (M2 - M1)/ $\mathrm{M} 2 \times 100$ was $0.34 \%$ during $2005-2006$ and $0.57 \%$ during 2006-2007 for TCRP, and $1.54 \%$ during 2005-2006 and $5.37 \%$ during 2006-2007 for TCRA, respectively. In other words, the mean rate of increase for these two cancer risks from 2005 to 2007 are $3.46 \% / y r$ for TCRA and $0.47 \% / y r$ for TCRP, respectively. If these two rates were constant in the next several decades, it could be predictable that, under the condition of moderate use of lindane within India and taking 2005 as the baseline year, the contributions of the Indian source to the TCRA will increase over 50\% from 2019 onward, and the contribution from Indian emission to the TCRP will increase $7 \%$ in 2019. This provides good evidence for the necessity of POP regulation to be the most important step to improve the environment and reduce the risk of human health and ecosystem under the Stockholm Convention on POPs. Reduction and termination of the use of POPs will also benefit global efforts to reduce trans-boundary transport; thereby benefiting downstream countries as well.

Using the three models, multiple modeling simulations have been carried out to assess the cancer risk in China subject to $\gamma$ $\mathrm{HCH}$ primary and secondary emissions from different sources across China and India during 2005-2007. While secondary emissions of $\gamma-\mathrm{HCH}$ from previously contaminated soils in China posed a higher cancer risk in China, the current use of lindane in India also contributed dramatically to the cancer risk in China. The results from this study further confirm significant influence of India $\gamma$-HCH emissions on Western China. Given that many POPs with strong LRAT potential were found to have higher air concentrations in India than in China, as reported in previous studies, ${ }^{14-17}$ their influence on human health risk and ecosystem contamination in China should not 
be overlooked, particularly in Western China where the atmospheric circulation systems (e.g., Indian monsoon) favor northeastward migration of contaminants from India.

\section{ASSOCIATED CONTENT}

\section{S Supporting Information}

Additional material as noted in the text. This material is available free of charge via the Internet at http://pubs.acs.org.

\section{AUTHOR INFORMATION}

\section{Corresponding Author}

*Phone: +86-535-2109-160; fax: +86-535-2109-000; e-mail: cgtian@yic.ac.cn.

\section{Notes}

The authors declare no competing financial interest.

\section{ACKNOWLEDGMENTS}

This work was supported by the Knowledge Innovation Program of the Chinese Academy of Sciences (No. KZCX2YW-GJ02), the Instrument Developing Project of the Chinese Academy of Sciences (No. YZ201161), the Promotive Research Foundation for Excellent Young and Middle-aged Scientists of Shandong Province (No. BS2012HZ028), and the Natural Scientific Foundation of China (Nos. 41101495 and 41125014). The authors gratefully acknowledge Global Soil Data Task and National Centers for Environmental Prediction for providing environmental data.

\section{REFERENCES}

(1) Jia, Y.; Stone, D.; Wang, W.; Schrlau, J.; Tao, S.; Simonich, S. L. M. Estimated reduction in cancer risk due to $\mathrm{PAH}$ exposures if source control measures during the 2008 Beijing Olympics were sustained. Environ. Health Perspect. 2011, 119 (6), 815-820.

(2) Sergeev, A. V.; Carpenter, D. O. Hospitalization rates for coronary heart disease in relation to residence near areas contaminated with persistent organic pollutants and other pollutants. Environ. Health Perspect. 2005, 113 (6), 756-761.

(3) Jansen, K. L.; Larson, T. V.; Koenig, J. Q.; Mar, T. F.; Fields, C.; Stewart, J.; Lippmann, M. Associations between health effects and particulate matter and black carbon in subjects with respiratory disease. Environ. Health Perspect. 2005, 113 (12), 1741-1746.

(4) Lee, D.-H.; Steffes, M. W.; Sjödin, A.; Jones, R. S.; Needham, L. L.; Jacobs, D. R., Jr. Low dose of some persistent organic pollutants predicts type 2 diabetes: A nested case-control study. Environ. Health Perspect. 2010, 118 (9), 1235-1242.

(5) Daar, A. S.; Singer, P. A.; Leah Persad, D.; Pramming, S. K.; Matthews, D. R.; Beaglehole, R.; Bernstein, A.; Borysiewicz, L. K.; Colagiuri, S.; Ganguly, N.; Glass, R. I.; Finegood, D. T.; Koplan, J.; Nabel, E. G.; Sarna, G.; Sarrafzadegan, N.; Smith, R.; Yach, D.; Bell, J. Grand challenges in chronic non-communicable diseases. Nature 2007, 450 (7169), 494-496.

(6) Li, L.; Rao, K.; Kong, L.; Yao, C.; Xiang, H.; Zhai, F.; Ma, G.; Yang, X. G. A description on the Chinese national nutrition and health survey in 2002. Chin. J. Epidemiol. 2005, 26 (7), 478-484.

(7) Ministry of Health of the People's Republic of China; China health statistics yearbook 2009; Peking Union Medical College Press: Beijing, 2010.

(8) Zhang, Y.; Tao, S.; Shen, H.; Ma, J. Inhalation exposure to ambient polycyclic aromatic hydrocarbons and lung cancer risk of Chinese population. Proc. Natl. Acad. Sci. U.S.A. 2009, 106 (50), 21063-21067.

(9) Zhou, Y.; Fu, J.; Zhuang, G.; Levy, J. Risk-based prioritization among air pollution control strategies in the Yangtze River Delta, China. Environ. Health Perspect. 2010, 118 (9), 1204-1210.
(10) Zhang, L.; Ma, J.; Venkatesh, S.; Li, Y.; Cheung, P. Modeling evidence of episodic intercontinental long-range transport of lindane. Environ. Sci. Technol. 2008, 42 (23), 8791-8797.

(11) Czub, G.; McLachlan, M. S. Bioaccumulation potential of persistent organic chemicals in humans. Environ. Sci. Technol. 2004, 38 (8), 2406-2412.

(12) McLachlan, M. S.; Czub, G.; MacLeod, M.; Arnot, J. A. Bioaccumulation of organic contaminants in humans: A multimedia perspective and the importance of biotransformation. Environ. Sci. Technol. 2010, 45 (1), 197-202.

(13) Xu, Y.; Tian, C.; Ma, J.; Zhang, G.; Li, Y.-F.; Ming, L.; Li, J.; Chen, Y.; Tang, J. Assessing environmental fate of $\beta-\mathrm{HCH}$ in Asian soil and association with environmental factors. Environ. Sci. Technol. 2012, 46 (17), 9525-9532.

(14) Zhang, G.; Chakraborty, P.; Li, J.; Sampathkumar, P.; Balasubramanian, T.; Kathiresan, K.; Takahashi, S.; Subramanian, A.; Tanabe, S.; Jones, K. C. Passive atmospheric sampling of organochlorine pesticides, polychlorinated biphenyls, and polybrominated diphenyl ethers in urban, rural, and wetland sites along the coastal length of India. Environ. Sci. Technol. 2008, 42 (22), 8218-8223.

(15) Pozo, K.; Harner, T.; Lee, S. C.; Wania, F.; Muir, D. C. G.; Jones, K. C. Seasonally resolved concentrations of persistent organic pollutants in the global atmosphere from the first year of the GAPS study. Environ. Sci. Technol. 2009, 43 (3), 796-803.

(16) Chakraborty, P.; Zhang, G.; Li, J.; Xu, Y.; Liu, X.; Tanabe, S.; Jones, K. C. Selected organochlorine pesticides in the atmosphere of major Indian cities: levels, regional versus local variations, and sources. Environ. Sci. Technol. 2010, 44 (21), 8038-8043.

(17) Pozo, K.; Harner, T.; Lee, S. C.; Sinha, R. K.; Sengupta, B.; Loewen, M.; Geethalakshmi, V.; Kannan, K.; Volpi, V. Assessing seasonal and spatial trends of persistent organic pollutants (POPs) in Indian agricultural regions using PUF disk passive air samplers. Environ. Pollut. 2011, 159 (2), 646-653.

(18) Liu, X.; Zhang, G.; Li, J.; Yu, L.; Xu, Y.; Li, X.; Kobara, Y.; Jones, K. C. Seasonal patterns and current sources of DDTs, chlordanes, hexachlorobenzene, and endosulfan in the atmosphere of 37 Chinese cities. Environ. Sci. Technol. 2009, 43 (5), 1316-1321.

(19) Gong, P.; Wang, X.; Sheng, J.; Yao, T. Variations of organochlorine pesticides and polychlorinated biphenyls in atmosphere of the Tibetan Plateau: Role of the monsoon system. Atmos. Environ. 2010, 44 (21-22), 2518-2523.

(20) Li, Y.; Macdonald, R. Sources and pathways of selected organochlorine pesticides to the Arctic and the effect of pathway divergence on $\mathrm{HCH}$ trends in biota: A review. Sci. Total Environ. 2005, 342 (1-3), 87-106.

(21) Abhilash, P.; Singh, N. Pesticide use and application: An Indian scenario. J. Hazard. Mater. 2009, 165 (1-3), 1-12.

(22) Hu, J.; Zhu, T.; Li, Q., Organochlorine pesticides in China. In Persistent Organic Pollutants in Asia: Sources, Distributions, Transport and Fate, Li, A.; Tanabe, S.; Jiang, G.; Giesy, J. P.; Lam, P. K. S., Eds.; Elsevier Ltd: Oxford, 2007; Vol. 7, pp 159-211.

(23) Ma, J.; Daggupaty, S.; Harner, T.; Li, Y. F. Impacts of lindane usage in the Canadian Prairies on the Great Lakes ecosystem. 1. Coupled atmospheric transport model and modeled concentrations in air and soil. Environ. Sci. Technol. 2003, 37 (17), 3774-3781.

(24) Kalnay, E.; Kanamitsu, M.; Kistler, R.; Collins, W.; Deaven, D.; Gandin, L.; Iredell, M.; Saha, S.; White, G.; Woollen, J.; Zhu, Y.; Leetmaa, A.; Reynolds, B.; Chellia, M.; Ebisuzaki, W.; Higgins, W.; Janowiak, J.; Mo, K.; Ropelewski, C.; Wang, J.; Jenne, R.; Joseph, D. The NCEP/NCAR reanalysis project. Bull. Am. Meteorol. Soc. 1996, 77, 437-471.

(25) Friedl, M. A.; McIver, D. K.; Hodges, J. C. F.; Zhang, X. Y.; Muchoney, D.; Strahler, A. H.; Woodcock, C. E.; Gopal, S.; Schneider, A.; Cooper, A.; Baccini, A.; Gao, F.; Schaaf, C. Global land cover mapping from MODIS: algorithms and early results. Remote Sens. Environ. 2002, 83 (1-2), 287-302.

(26) Qiu, X.; Zhu, T.; Wang, F.; Hu, J. Air-water gas exchange of organochlorine pesticides in Taihu Lake, China. Environ. Sci. Technol. 2008, 42 (6), 1928-1932. 
(27) Gao, J.; Liu, L.; Liu, X.; Lu, J.; Zhou, H.; Huang, S.; Wang, Z.; Spear, P. Occurrence and distribution of organochlorine pesticideslindane, $\mathrm{p}, \mathrm{p}^{\prime}$-DDT, and heptachlor epoxide-in surface water of China. Environ. Int. 2008, 34 (8), 1097-1103.

(28) McKone, T. CalTOX, a multimedia total exposure model for hazardous-waste sites; Part I: executive summary; Department of Toxic Substances Control, Lawrence Livermore Nationnal Laboratory, Livemore, CA, 1993; pp UCRL-CR-111456:31.

(29) Tao, S.; Yang, Y.; Cao, H.; Liu, W.; Coveney, R.; Xu, F.; Cao, J.; Li, B.; Wang, X.; Hu, J.; Fang, J. Modeling the dynamic changes in concentrations of gamma-hexachlorocyclohexane (gamma-HCH) in Tianjin region from 1953 to 2020. Environ. Pollut. 2006, 139 (1), 183193.

(30) Hewitt, R.; Forero, A.; Luncsford, P. J.; Martin, F. L. Enhanced micronucleus formation and modulation of Bcl-2:Bax in MCF-7 cells after exposure to binary mixtures. Environ. Health Perspect. 2007, 115 (S-1), 129-136.

(31) Guo, M.; Tao, S.; Yang, Y.; Li, B.; Cao, J.; Wang, X.; Liu, W.; $\mathrm{Xu}, \mathrm{F}$.; $\mathrm{Wu}, \mathrm{Y}$. Population exposure to $\mathrm{HCH}$ in Tianjin area. Environ. Sci. 2005, 26 (1), 164-167.

(32) Yu, Y.; Tao, S.; Liu, W.; Lu, X.; Wang, X.; Wong, M. Dietary intake and human milk residues of hexachlorocyclohexane isomers in two Chinese cities. Environ. Sci. Technol. 2009, 43 (13), 4830-4835.

(33) Liu, D.; Qiu, W.; Xia, Z.; Wang, B.; Lu, X.; Duan, X.; Jiang, Q.; $\mathrm{Lu}, \mathrm{B}$.; Song, Y.; Hu, X.; Tao, S. Oral intake of lindane by population in Taiyuan. Asian J. Ecotoxicol 2009, 6 (4), 786-792.

(34) Tian, C.; Ren, N.; Ma, J.; Li, Y. Sources of $\gamma-\mathrm{HCH}$ in Chinese air at near-surface level and deposited to Chinese soil. Chin. Environ. Sci. 2009, 29 (9), 897-901.

(35) Liu, W.; Chen, D.; Liu, X.; Zheng, X.; Yang, W.; Westgate, J.; Wania, F. Transport of semivolatile organic compounds to the Tibetan plateau: Spatial and temporal variation in air concentrations in mountainous western Sichuan, China. Environ. Sci. Technol. 2010, 44 (5), 1559-1565.

\section{NOTE ADDED AFTER ASAP PUBLICATION}

This article was published ASAP on June 11, 2013, with an error in the Abstract and Table of Contents graphics. The corrected version was published ASAP on June 19, 2013. 